\title{
Effect of bovine oviductal extracellular vesicles on embryo development and quality in vitro
}

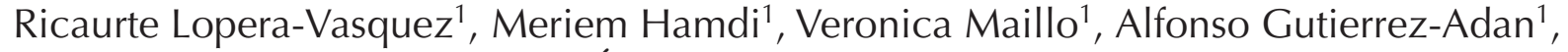 \\ Pablo Bermejo-Alvarez ${ }^{1}$, Miguel Ángel Ramírez¹, María Yáñez-Mó ${ }^{2,3}$ and Dimitrios Rizos ${ }^{1}$ \\ ${ }^{1}$ Departamento de Reproduccion Animal, Instituto Nacional de Investigacion y Tecnologia Agraria y Alimentaria \\ (INIA), Madrid, Spain, ${ }^{2}$ Unidad de Investigacion Hospital Santa Cristina, Instituto de Investigaciones Sanitarias \\ Princesa (IIS-IP), Madrid, Spain and ${ }^{3}$ Departamento de Biologia Molecular, UAM/CBM-SO, Madrid, Spain
}

Correspondence should be addressed to D Rizos; Email: drizos@inia.es

\begin{abstract}
The aim of this study was to evaluate the effect of extracellular vesicles (EV) from oviductal fluid (OF), either from the ampulla or isthmus, on the development and quality of in vitro-cultured bovine embryos. Zygotes were cultured in synthetic oviduct fluid (SOF $+3 \mathrm{mg} / \mathrm{mL} \mathrm{BSA}$ ) without calf serum (C- group), in the presence of $3 \times 10^{5} \mathrm{EV} / \mathrm{mL}$ from ampullary or isthmic OF at either $1 \times 10^{4} \mathrm{~g}$ $(10 \mathrm{~K})$ or $1 \times 10^{5} \mathrm{~g}(100 \mathrm{~K})$, and compared with SOF + $5 \%$ FCS (C+ group). OF-EV size and concentration were assessed by electron microscopy and nanotracking analysis system. Embryo development was recorded on Days 7-9, and blastocyst quality was assessed through cryotolerance and gene expression analysis. Lower blastocyst yield was observed on Day 7 in the C- and OF-EV groups (12.0-14.3\%) compared with C+ (20.6\%); however, these differences were compensated at Days 8 and 9 (Day 9: 28.5-30.8\%). Importantly, the survival rate of blastocysts produced with isthmic $100 \mathrm{~K}$ OF-EV was higher than that of $\mathrm{C}+$ and $\mathrm{C}-$ group at $72 \mathrm{~h}$ after vitrification and warming $(\mathbf{8 0 . 1}$ vs 34.5 and $50.5 \%$ respectively, $P<0.05)$. In terms of gene expression, blastocysts produced in the presence of $100 \mathrm{~K}$ isthmic OF-EV upregulated the water channel AQP3 and DNMT3A and SNRPN transcripts compared with the C+, with the expression in $\mathrm{C}$ - being intermediate. The lipid receptor $L D L R$ was downregulated in $\mathrm{C}+$ compared with all other groups. In conclusion, the addition of oviductal fluid extracellular vesicles from isthmus, to in vitro culture of bovine embryos in the absence of serum improves the development and quality of the embryos produced.
\end{abstract}

Reproduction (2017) 153 461-470

\section{Introduction}

Despite considerable improvements in assisted reproductive technologies in the last several decades, conditions of in vitro embryo production are far from the physiological (Lonergan \& Fair 2008). The in vitro deficiencies are reflected in lower embryo developmental rates and quality of the blastocysts produced when compared to their in vivo counterparts (Lonergan 2007), evidenced by lower cryotolerance (Rizos et al. 2008), altered inner cell mass/trophectoderm cell ratio (Plourde et al. 2012), altered gene expression patterns (Niemann \&Wrenzycki 2000) and lower pregnancy rates of transferred embryos (Pontes et al. 2009). Biological complements added to culture media, such as serum and serum albumin, improve embryo developmental rates. However, it has been shown that serum exhibits a biphasic effect, increasing the number of transferable embryos but reducing their quality reflected in short(Rizos et al. 2003) and/or long-term effects such as large offspring syndrome (Lazzari et al. 2002).
The oviduct is a dynamic organ where fertilization and early embryo development takes place. Regulatory mechanisms modulate the fluidic milieu composition to allow sperm capacitation, transport and fertilization of the mature oocyte in the ampulla and early embryonic development in the isthmus (Leese et al. 2007, Rodriguez-Martinez 2007). It has been shown that the oviductal environment can support embryonic growth up to the blastocyst stage and produce better-quality embryos across a wide range of species after transspecies transfer (Rizos et al. 2010). Moreover, the use in vitro of oviductal epithelial cells (OEC) allows the study of mechanisms involved in sperm storage in the oviduct (Abe \& Hoshi 1997) and the embryotrophic effects on early embryo development and quality (Cordova et al. 2014). Thus, the use of in vitro models can provide evidence on physiological embryomaternal interactions, mechanisms that are difficult to study in vivo.

The OF is generated by transudation from plasma into the oviductal lumen supplemented with secreted substances from OEC (Menezo \& Guerin 1997). 
Secretions present in the OF affect oocyte and sperm function (Killian 2011, Mondéjar et al. 2013) and comprise proteins, such as glycodelins and lactoferrin, involved in gamete interaction (Ghersevich et al. 2015), oviductin, osteopontins and the complement protein C3 important for early embryo development (Tse et al. 2008), and oviductal glycoprotein 1 (OVGP1) important for sperm-zona pellucida binding (Coy et al. 2012). The use of pure bovine OF during in vitro maturation of porcine oocytes prior to fertilization improves embryo development and quality, protecting them against adverse impacts of mtDNA transcription/replication and apoptosis induced by the culture environment (Lloyd et al. 2009). In contrast in cattle, OF treatment of matured oocytes had no effect on fertilization parameters, cleavage rate, blastocyst yield or morphology. However, several gene transcripts related to embryo quality were upregulated in blastocysts (Cebrian-Serrano et al. 2013). When bovine zygotes were cultured in vitro with low concentrations of OF $(1.25 \%$ and $0.625 \%)$, it was demonstrated that OF had a positive effect on the development and quality of the produced blastocysts (Lopera-Vasquez et al. 2015).

Extracellular vesicles (EVs) play an important role in intercellular communication and the regulation of physiological and pathological processes (for review, see Yanez-Mo et al. 2015). They contain and may transfer different bioactive molecules (proteins, mRNAs, miRNAs (Simons \& Raposo 2009, Silveira et al. 2012) and lipids (Raposo \& Stoorvogel 2013)). EV nomenclature commonly relates to $\mathrm{EV}$ size and origin, and includes exosomes $(30-200 \mathrm{~nm})$ of endosomal origin and microvesicles (MV) (100-1000 nm), those $\mathrm{EV}$ that bud from the plasma membrane. These major vesicle subtypes are commonly enriched by differential centrifugation (Théry et al. 2006). Smaller vesicles are typically isolated by sedimentation at 100,000-200,000 g (100-200 K) (Théry et al. 2009), whereas $\mathrm{MVs}$ are typically reported to be enriched at 10,000-20,000 g (10-20 K) (Witwer et al. 2013).

EVs have been identified in vivo in all body fluids studied including amniotic fluid, urine and blood (Simpson et al. 2008). Regarding reproduction, EVs have been reported in follicular fluid (Silveira et al. 2012), uterine fluid (Burns et al. 2014) endometrial environment ( $\mathrm{Ng}$ et al. 2013) and seminal plasma (Piehl et al. 2013). Saadeldin and coworkers (Saadeldin et al. 2014) showed that the addition of exosomes isolated from the conditioned medium of parthenogenetic embryos increased the developmental competence of cloned embryos. Recently, we provided evidence that EV derived from media conditioned by bovine oviduct epithelial cells (BOEC) improves blastocyst quality and induces cryoprotection in in vitro culture to the same extent as classical co-culture with fresh BOEC monolayers (Lopera-Vásquez et al. 2016).
Thus, the aim of the present study was to isolate EV from bovine OF and evaluate their effect on early embryonic development and quality of the blastocysts in vitro. This may contribute to the improvement of assisted reproduction technologies in mammals and humans as well as providing new insights on early embryo-maternal communication.

\section{Materials and methods}

Unless otherwise stated, all chemicals were purchased from Sigma Aldrich Química S.A.

\section{Extracellular vesicle isolation}

Ipsilateral oviducts from slaughtered heifers at the early or mid-luteal phase of the estrous cycle (based on corpus luteum morphology) were transported to the laboratory on ice. All oviducts were washed twice in PBS, and trimmed free of tissue on a cooled surface. The ampulla and isthmus were separated through the ampullary-isthmic junction, identified where the oviduct diameter first exhibited a marked reduction in size. Each oviductal region (ampulla and isthmus) was washed with $5 \mathrm{~mL}$ of PBS $\left(4^{\circ} \mathrm{C}\right)$. After a first centrifugation for BOEC elimination $(400 \mathrm{~g})$, EV were pelleted under two sequential centrifugal (g) forces: (i) $10,000 \mathrm{~g}(10 \mathrm{~K})$ and (ii) $100,000 \mathrm{~g}(100 \mathrm{~K})$ following the procedures of Théry and coworkers (Théry et al. 2006) with minor modifications. Briefly, after BOEC removal, the OF was centrifuged at $10 \mathrm{~K}$ for $60 \mathrm{~min}$ at $4^{\circ} \mathrm{C}$. Then, the supernatant was removed and centrifuged again at $100 \mathrm{~K}$ for 60 min at $4^{\circ} \mathrm{C}$ and the resultant pellet was recovered (Avanti J30i, Beckman Coulter). The EV recovered at $10 \mathrm{~K}$ and $100 \mathrm{~K}$ $\boldsymbol{g}$-forces were washed in PBS and pelleted again under the previous conditions.

\section{EV characterization}

\section{Nanoparticle tracking analysis (NTA)}

A representative part $(100 \mu \mathrm{L})$ of the resultant pellet $(\approx 400 \mu \mathrm{L}$ obtained vesicles) was used to determine the size and number of EV by NTA with Nanosight LM10 and NTA 2.3 Software (Nanosight, Wiltshire, UK). EV concentration was standardized, and samples were frozen for embryo culture.

\section{Transmission electron microscopy (EM)}

For negative staining of exosomes, ionized carbon and collodion-coated copper EM grids were floated on a sample drop, washed and stained with $2 \%$ uranyl acetate (in doubledistilled water) for $1 \mathrm{~min}$ and visualized in a JEM-1010 (JEOL, Tokyo, Japan) transmission EM.

\section{Western blot}

EV preparations were lysed in non-reducing Laemmli loading buffer and resolved in a $4-25 \%$ gradient SDS-PAGE gel (Biorad). Proteins were transferred to a PVDF membrane (Biorad), blocked with $10 \%$ skimmed milk and incubated 
with the following primary antibodies: anti-CD $9 \mathrm{mAb}$ VJ1/20, anti-ERM 90:3 pAb and anti-TSG101 mab (Abcam) (Lopera-Vásquez et al. 2016) followed by peroxidasecoupled secondary antibodies and revealed detected by chemiluminescence with an ImageQuant LAS4000 biomolecular imager (GE LifeSciences).

\section{In vitro embryo production}

\section{Oocyte collection and in vitro maturation}

Immature cumulus oocyte complexes (COCs) were obtained by aspirating follicles $(2-8 \mathrm{~mm})$ from the ovaries of postpubertal heifers and cows collected at slaughter. Class 1 and 2 COCs were matured for $24 \mathrm{~h}$ in $500 \mu \mathrm{L}$ of maturation media (TCM 199 supplemented with $10 \%$ (v/v) fetal calf serum (FCS) and $10 \mathrm{ng} / \mathrm{mL}$ epidermal growth factor) in a four-well dish, in groups of $50 \mathrm{COCs}$ per well at $38.5^{\circ} \mathrm{C}$ under an atmosphere of $5 \% \mathrm{CO}_{2}$ in air, with maximum humidity.

\section{Sperm preparation and in vitro fertilization}

Frozen semen from a previously tested Asturian Valley bull (ASEAVA, Asturias, Spain) was thawed at $37^{\circ} \mathrm{C}$ in a water bath for $1 \mathrm{~min}$ and centrifuged for $10 \mathrm{~min}$ at $280 \mathrm{~g}$ through a gradient of $1 \mathrm{~mL}$ of $40 \%$ and $1 \mathrm{~mL}$ of $80 \%$ Bovipure according to the manufacturer's specification (Nidacon Laboratories AB, Göthenborg, Sweden). The sperm pellet was isolated and washed in $3 \mathrm{~mL}$ of Boviwash (Nidacon) by centrifugation at $280 \mathrm{~g}$ for $5 \mathrm{~min}$. The pellet was re-suspended in the remaining $300 \mu \mathrm{L}$ of Boviwash. Sperm concentration was determined and adjusted to a final concentration of $1 \times 10^{6} \mathrm{sperm} / \mathrm{mL}$ for IVF. Gametes were co-incubated for $18-22 \mathrm{~h}$ in $500 \mu \mathrm{L}$ of fertilization media (Tyrode's medium with $25 \mathrm{mM}$ bicarbonate, $22 \mathrm{mM} \mathrm{Na}$ lactate, $1 \mathrm{mM}$ Na-pyruvate, and $6 \mathrm{mg} / \mathrm{mL}$ fatty acidfree BSA supplemented with $10 \mathrm{mg} / \mathrm{mL}$ heparin sodium salt, Calbiochem) in a four-well dish, in groups of 50 COCs per well under an atmosphere of $5 \% \mathrm{CO}_{2}$ in air, with maximum humidity at $38.5^{\circ} \mathrm{C}$.

In vitro culture of presumptive zygotes

At approximately $20 \mathrm{~h}$ after insemination (p.i.), presumptive zygotes were denuded of cumulus cells by vortex and cultured in $500 \mu \mathrm{L}$ of Synthetic Oviduct Fluid, (SOF) (Holm et al. 1999) (with $4.2 \mathrm{mM}$ sodium lactate, $0.73 \mathrm{mM}$ sodium pyruvate, $30 \mu \mathrm{L} / \mathrm{mL}$ BME amino acids, $10 \mu \mathrm{L} / \mathrm{mL}$ MEM amino acids, $1 \mu \mathrm{g} /$ $\mathrm{mL}$ phenol-red) with or without OF-EV (see 'Experimental design' section for clarification) in a four-well dish, covered with mineral oil, in groups of 50 per well, at $38.5^{\circ} \mathrm{C}$ under an atmosphere of $5 \% \mathrm{CO}_{2}, 5 \% \mathrm{O}_{2}$ and $90 \% \mathrm{~N}_{2}$. When stated, SOF was supplemented with $3 \mathrm{mg} / \mathrm{mL}$ BSA (A9647 - Sigma) or 5\% FCS (F2442 - Sigma).

\section{Assessment of embryo development and quality}

Embryo development

Cleavage rate was recorded at Day 2 (48 h p.i.), and cumulative blastocyst yield was recorded at Days 7, 8 and 9 p.i. under a stereomicroscope.

\section{Embryo quality}

\section{Blastocyst vitrification}

The ability of the blastocyst to withstand cryopreservation was used as a quality indicator. Days 7 and 8 blastocysts were vitrified in holding medium (HM) (TCM199 supplemented with $20 \%$ (v/v) FCS) and cryoprotectants, following the procedures of Rizos and coworkers (Rizos et al. 2002), in a two-step protocol using the Cryloop device (Hampton Research, Aliso Viejo, CA, USA). First step: HM with $7.5 \%$ ethylene glycol, $7.5 \%$ dimethyl sulfoxide and second-step final solution: HM with $16.5 \%$ ethylene glycol, $16.5 \%$ dimethyl sulfoxide and

Table 1 Details of primers used for qRT-PCR.

\begin{tabular}{|c|c|c|c|c|}
\hline Gene & & Primer sequence $\left(5^{\prime}-3^{\prime}\right)$ & Fragment size (bp) & Gene bank accession no. \\
\hline \multirow[t]{2}{*}{ H2A.Z } & Forward & AGGACGACTAGCCATGGACGTGTG & 212 & NM_016750 \\
\hline & Reverse & CCACCACCAGCAATTGTAGCCTTG & & \\
\hline \multirow[t]{2}{*}{$A Q P 3$} & Forward & CGGTGGTTTCCTCACCATCA & 299 & NM_001079794.1 \\
\hline & Reverse & CAGAGGGGTAGGTGGCAAAG & & \\
\hline \multirow[t]{2}{*}{$A Q P 11$} & Forward & GCTTCGTATCCACCTGCTGT & 102 & NM_001110069.1 \\
\hline & Reverse & TGCAGTGAAAGTGCCAAAGT & & \\
\hline \multirow[t]{2}{*}{ ATP1A1 } & Forward & GCGGACACGACAGAGAATCA & 158 & NM_001076798.1 \\
\hline & Reverse & GAGGCATCACCCGCTACAG & & \\
\hline \multirow[t]{2}{*}{$L D L R$} & Forward & CAAAACCCCGATCATCCССА & 194 & NM_001166530 \\
\hline & Reverse & TCGACCСТGAACTGGAAACG & & \\
\hline \multirow[t]{2}{*}{$\angle D H A$} & Forward & TTCTTAAGGAAGAACATGTC & 310 & NM_174099.2 \\
\hline & Reverse & TTCACGTTACGCTGGACCAA & & \\
\hline \multirow[t]{2}{*}{ DNMT3A } & Forward & СTGGTGCTGAAGGACTTGGGC & 318 & AY271299 \\
\hline & Reverse & CAGAAGAAGGGGCGGTCATC & & \\
\hline \multirow[t]{2}{*}{$I G F 2 R$} & Forward & GCTGCGGTGTGCCAAGTGAAAAAG & 201 & NM_174352.2 \\
\hline & Reverse & AGCСССТСTGССGTTGTTACСT & & \\
\hline \multirow[t]{2}{*}{ GRB10 } & Forward & GAAGACGGGACAAGCAAAGT & 291 & XM_010803961.1 \\
\hline & Reverse & CTGGCACCACGTAACCATCTG & & \\
\hline \multirow[t]{2}{*}{$S N R P N$} & Forward & AACAGCACGTACCAGAGGTG & 144 & NM_001079797.1 \\
\hline & Reverse & ATGCCTGTCTCAGTTCTGCC & & \\
\hline
\end{tabular}


$0.5 \mathrm{M}$ sucrose. The blastocysts were warmed in two steps in $\mathrm{HM}$ with $0.25 \mathrm{M}$ and $0.15 \mathrm{M}$ sucrose and then cultured in $25 \mu \mathrm{L}$ droplets of SOF with $5 \%$ FCS. Survival was defined as re-expansion of the blastocoel and its maintenance for 24, 48 and $72 \mathrm{~h}$.

\section{Gene expression analysis}

Poly(A) RNA was extracted from five pools of 10 blastocysts from each experimental group using the Dynabeads mRNA Direct Extraction Kit (Dynal Biotech, Oslo, Norway) with minor modifications (Bermejo-Álvarez et al. 2008). Immediately after extraction, the RT reaction was carried out following the manufacturer's instructions (Bioline, Ecogen, Madrid, Spain) using poly $(\mathrm{T})$ primer, random primers and MMLV reverse transcriptase enzyme. The quantification of all mRNA transcripts was carried out by qPCR with two repetitions for all genes of interest. qPCR was performed by adding a $2 \mu \mathrm{L}$ aliquot of each cDNA sample to the PCR mix containing the specific primers. All primers were designed using Primer-BLAST software to span exon-exon boundaries when possible (http:// www.ncbi.nlm.nih.gov/tools/primer-blast/). Primer sequences and the approximate sizes of the amplified fragments of all transcripts are shown in Table 1. For quantification, qPCR was performed as described previously (Bermejo-Alvarez et al. 2010); PCR conditions were tested to achieve efficiencies close to 1 . The comparative cycle threshold (CT) method was used to quantify expression levels. Values were normalized to the endogenous control, H2AFZ. Fluorescence was acquired in each cycle to determine the threshold cycle or the cycle during the log-linear phase of the reaction at which fluorescence increased above background for each sample. Within this region of the amplification curve, a difference of one cycle is equivalent to a doubling of the amplified PCR product. According to the comparative CT method, the $\triangle \mathrm{CT}$ value was determined by subtracting the $H 2 A F Z C T$ value for each sample from each gene CT value of the sample. The calculation of $\Delta \Delta \mathrm{CT}$ involved using the highest treatment $\Delta \mathrm{CT}$ value, i.e., the treatment with the lowest target expression, as an arbitrary constant to subtract from all other $\Delta \mathrm{CT}$ sample values. Fold changes in the relative gene expression of the target were determined using the formula $2^{-\Delta \Delta \mathrm{CT}}$.

\section{Experimental design}

The developmental capacity of bovine zygotes and the quality of the produced blastocysts cultured in vitro with EV from

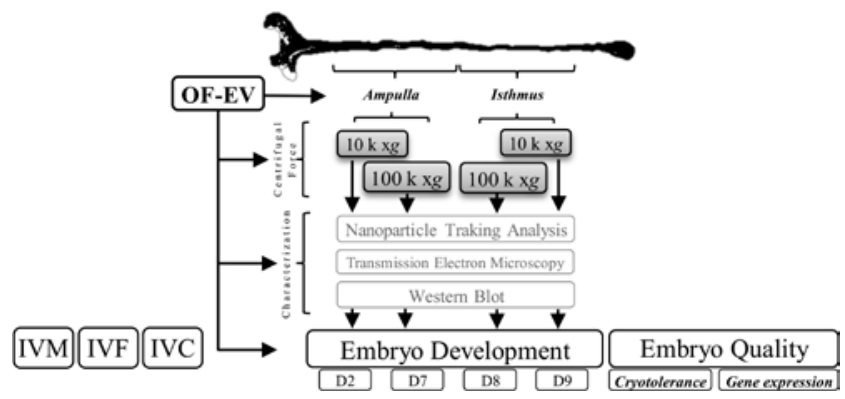

Figure 1 Experimental design.
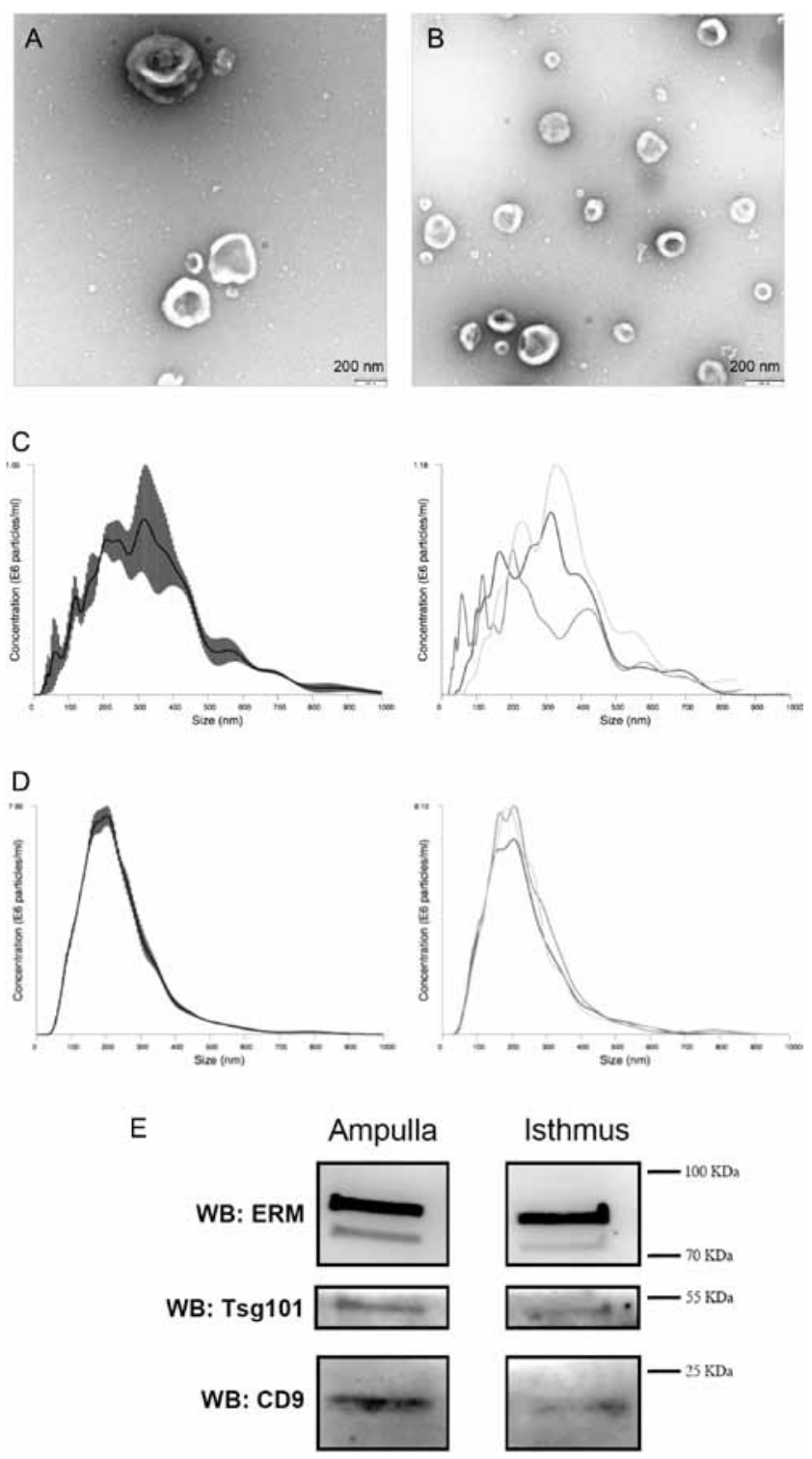

Isthmus

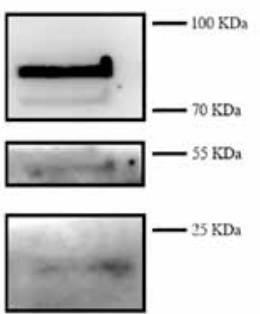

Figure 2 Electron microscope images and NTA analyses of OF-EV isolated at $10 \mathrm{~K}$ (A and C) and $100 \mathrm{~K}$ (B and D) $\boldsymbol{g}$-forces. Western blot analysis of OF-EV with EV markers (E).

OF of the ampulla (A) and the isthmus (I) from early luteal phase obtained at $10,000 \mathrm{~g}(10 \mathrm{~K})$ and $100,000 \mathrm{~g}(100 \mathrm{~K})$ was assessed (Fig. 1). At approximately $20 \mathrm{~h}$ after insemination, presumptive zygotes were cultured with frozen/thawed

Table 2 Concentration OF-EV isolated from OF at different cycle phases at different $\boldsymbol{g}$-forces (10-100 K).

\begin{tabular}{lccc}
\hline Luteal phase & Centrifugal force $(\boldsymbol{g})$ & $\boldsymbol{n}$ & Concentration* $^{*}$ \\
\hline Early (Day 1-4) & $10 \mathrm{~K}$ & 5 & $2.8 \pm 1.2^{\mathrm{a}}$ \\
& $100 \mathrm{~K}$ & 5 & $9.28 \pm 4.1^{\mathrm{b}}$ \\
Medium (Day 4-8) & $10 \mathrm{~K}$ & 5 & $1.25 \pm 0.3^{\mathrm{a}}$ \\
& $100 \mathrm{~K}$ & 5 & $3.98 \pm 0.5^{\mathrm{a}}$ \\
\hline
\end{tabular}

$n$ : Number of oviductal samples used in nanoparticle analysis system (Nanosight). K: Represents $1 \times 10^{3}$.

${ }^{*}$ EV particles $8 / \mathrm{mL} \pm$ s.D. ${ }^{\mathrm{a}, \mathrm{b}, \mathrm{c}}$ Values in the same column with different superscripts differ significantly $(P<0.05)$. 
Table 3 Concentration OF-EV isolated from the ampulla and the isthmus at different $\boldsymbol{g}$-forces (10-100 K).

\begin{tabular}{lcc}
\hline Centrifugal force $(\boldsymbol{g})$ & $\boldsymbol{n}$ & Concentration* \\
\hline Ampulla & & \\
$10 \mathrm{~K}$ & 3 & $9.0 \pm 3.4^{\mathrm{ab}}$ \\
$100 \mathrm{~K}$ & 3 & $10.5 \pm 3.1^{\mathrm{b}}$ \\
Isthmus & & \\
$10 \mathrm{~K}$ & 3 & $3.6 \pm 2.5^{\mathrm{ac}}$ \\
$100 \mathrm{~K}$ & 3 & $7.5 \pm 0.2^{\mathrm{ab}}$ \\
\hline
\end{tabular}

$n$ : Number of oviductal samples used in nanoparticle analysis system (Nanosight). K: Represents $1 \times 10^{3}$.

${ }^{*}$ EV Particles $/ \mathrm{mL} \pm$ S.D. ${ }^{a, b, c}$ Values in the same column with different superscripts differ significantly $(P<0.05)$.

OF-EV from the ampulla and isthmus isolated at $10 \mathrm{~K}$ and $100 \mathrm{~K}$ and diluted in SOF supplemented with $3 \mathrm{mg} / \mathrm{mL}$ BSA (C-) under adjusted concentration of $3 \times 10^{5} \mathrm{EV} / \mathrm{mL}$. A group of SOF supplemented with $5 \%$ fetal calf serum was included (C+). Embryo development was assessed on Days 7, 8 and 9. To assess blastocyst quality a representative number of Days 7-8 blastocysts from each group were either vitrified/ warmed, and survival rate was recorded every $24 \mathrm{~h}$ up to $72 \mathrm{~h}$ after warming or frozen in $\mathrm{LN}_{2}$ in groups of 10 and stored at $-80^{\circ} \mathrm{C}$ for gene expression analysis. A total of 11 replicates were carried out.

\section{Statistical analysis}

Results of EV concentration, cleavage rate, blastocyst yield, survival after vitrification/warming and relative mRNA abundance for candidate genes were analyzed using oneway ANOVA $(P<0.05)$. All analyses were performed with the SigmaStat software package (Jandel Scientific, San Rafael, CA, USA).

\section{Results}

\section{Oviductal fluid contains extracellular vesicles}

Extracellular vesicles were enriched from OF by ultracentrifugation at two different centrifugal forces $(10 \mathrm{~K}$ and $100 \mathrm{~K})$. Transmission electron microscopy revealed a larger (with some vesicles larger than $500 \mathrm{~nm}$ ) and more scarce vesicle population in the $10 \mathrm{~K}$ pellet, whereas the $100 \mathrm{~K}$ pellet was mainly composed of smaller vesicles of less than $200 \mathrm{~nm}$ of diameter (Fig. 2A and $\mathrm{B}$ respectively). Nanosight analyses confirmed a broader size distribution in the $10 \mathrm{~K}$ pellet, encompassing vesicles larger than $500 \mathrm{~nm}$, whereas the $100 \mathrm{~K}$ pellet revealed a more homogeneous and smaller distribution (Fig. 2C and D respectively). These vesicles expressed some of the classical markers described for exosomes (ERM, TSG101 and tetraspanin CD9 proteins) (Lopera-Vásquez et al. 2016) (Fig. 2E). Regarding vesicle number, the $100 \mathrm{~K}$ pellet contained more vesicles than the $10 \mathrm{~K}$ pellet, this difference being more evident in the early phase of the estrous cycle (Table 2). Because the early embryo is still in the oviduct during the early luteal phase, we thereafter focused on this early phase isolating OF from either the isthmus or the ampulla section of the oviduct for the present experiment. These analyses revealed that in the ampulla, vesicles were more or less equally divided in the $10 \mathrm{~K}$ and the $100 \mathrm{~K}$ pellet, whereas the isthmus had a higher concentration of smaller vesicles mainly recovered in the $100 \mathrm{~K}$ pellet (Table 3 ).

\section{Extracellular vesicles isolated from isthmus OF have a positive effect on the quality of in vitro-produced bovine embryos}

Addition of OF-derived EV to in vitro embryo culture resulted in no differences in terms of cleavage rates (range: $88.0-89.6 \%$ ) and blastocysts yield at Day 8 (range: $24.6-26.9 \%$ ) and Day 9 (range: $28.5-30.8 \%$ ), as shown in Table 4. As previously reported, the blastocyst yield at Day 7 in the C+ group was significantly higher $(20.6 \%)$ compared with the rest of the groups (range: 12.0-14.3\%) $(P<0.05)$.

Interestingly, the survival rate at $24 \mathrm{~h}$ after vitrification/warming of blastocysts produced with $100 \mathrm{~K}$ OF-EV from isthmus was significantly higher than $\mathrm{C}+, \mathrm{C}-$ and ampulla-10 $\mathrm{K}$ groups $(91.3 \%$ vs $48.3 \%$; $71.0 \% ; 62.2 \%$ respectively, $P<0.05)$. At 48 and $72 \mathrm{~h}$, these differences were increased with a survival rate of isthmus- $100 \mathrm{~K}$ group of $80-89 \%$. The survival rate of the blastocysts from isthmus- $10 \mathrm{~K}$ group was also significantly higher than that in $\mathrm{C}+\mathrm{at}$ all time points (Table 5).

Table 4 Effect of in vitro embryo culture with OF-EV (ampulla-isthmus) isolated at different g-forces (10-100 K $\times$ g) on development in vitro.

\begin{tabular}{|c|c|c|c|c|c|c|}
\hline & \multirow[b]{2}{*}{ Centrifugal force $(g)$} & \multirow[b]{2}{*}{$n$} & \multirow[b]{2}{*}{ Cleavage* $^{*}$} & \multicolumn{3}{|c|}{ Blastocyst yield* } \\
\hline & & & & Day 7 & Day 8 & Day 9 \\
\hline Control (C+) & & 490 & $432(88.5 \pm 2.2)$ & $99(20.6 \pm 2.1)^{\mathrm{a}}$ & $129(26.9 \pm 1.9)$ & $143(29.6 \pm 2.3)$ \\
\hline Control (C-) & & 566 & $498(88.1 \pm 1.3)$ & $75(13.4 \pm 1.8)^{b}$ & $139(24.6 \pm 1.7)$ & $168(29.7 \pm 2.5)$ \\
\hline \multirow[t]{2}{*}{ Ampulla } & $10 \mathrm{~K}$ & 514 & $460(89.6 \pm 1.3)$ & $62(12.0 \pm 1.6)^{b}$ & $133(26.0 \pm 2.1)$ & $152(29.7 \pm 2.1)$ \\
\hline & $100 \mathrm{~K}$ & 462 & $406(88.0 \pm 1.1)$ & $63(13.8 \pm 1.9)^{b}$ & $116(25.3 \pm 2.4)$ & $131(28.5 \pm 2.2)$ \\
\hline \multirow[t]{2}{*}{ Isthmus } & $10 \mathrm{~K}$ & 557 & $494(88.6 \pm 1.5)$ & $75(13.7 \pm 1.1)^{b}$ & $135(24.6 \pm 2.2)$ & $164(29.6 \pm 1.9)$ \\
\hline & $100 \mathrm{~K}$ & 549 & $488(89.1 \pm 1.2)$ & $68(14.3 \pm 3.0)^{b}$ & $126(26.1 \pm 4.1)$ & $151(30.8 \pm 4.5)$ \\
\hline
\end{tabular}

K: Represents $1 \times 10^{3}$.

*Results presented as $n(\% \pm$ S.E.) where $n$ represents total number of presumptive zygotes placed in culture. a,b Values in the same column with different superscripts differ significantly $(P<0.05)$. 
Table 5 Survival rate after vitrification and warming of D7-8 blastocyst cultured with OF-EV (ampulla-isthmus) isolated at different $\mathbf{g}$-forces $(10-100 \mathrm{~K} \times \mathbf{g})$.

\begin{tabular}{|c|c|c|c|c|c|c|}
\hline & \multirow[b]{2}{*}{ Centrifugal force $(g)$} & \multirow[b]{2}{*}{$n$} & \multicolumn{4}{|c|}{ Blastocyst survival after vitrification/warming* } \\
\hline & & & $4 \mathrm{~h}$ & $24 \mathrm{~h}$ & $48 \mathrm{~h}$ & $72 \mathrm{~h}$ \\
\hline Control (C+) & & 80 & $65(80.4 \pm 5.2)$ & $43(48.3 \pm 9.1)^{\mathrm{a}}$ & $37(41.3 \pm 7.0)^{\mathrm{a}}$ & $31(34.5 \pm 8.0)^{\mathrm{a}}$ \\
\hline Control (C-) & & 105 & $92(87.6 \pm 4.5)$ & $77(71.0 \pm 6.6)^{\mathrm{ab}}$ & $64(58.0 \pm 7.7)^{\mathrm{ab}}$ & $56(50.5 \pm 8.1)^{\mathrm{ab}}$ \\
\hline \multirow{2}{*}{ Ampulla } & $10 \mathrm{~K}$ & 88 & $78(85.9 \pm 4.6)$ & $61(62.2 \pm 10.4)^{\mathrm{ab}}$ & $52(50.8 \pm 11.5)^{\mathrm{ab}}$ & $48(46.3 \pm 12.2)^{\mathrm{ab}}$ \\
\hline & $100 \mathrm{~K}$ & 64 & $59(89.9 \pm 3.6)$ & $50(73.5 \pm 7.4)^{\mathrm{abc}}$ & $49(71.9 \pm 7.7)^{\mathrm{bc}}$ & $45(66.8 \pm 7.6)^{\mathrm{bc}}$ \\
\hline \multirow[t]{2}{*}{ Isthmus } & $10 \mathrm{~K}$ & 119 & $114(96.6 \pm 1.8)$ & $100(83.6 \pm 4.7)^{\mathrm{bc}}$ & $93(78.6 \pm 3.3)^{\mathrm{bc}}$ & $86(70.5 \pm 4.4)^{\mathrm{bc}}$ \\
\hline & $100 \mathrm{~K}$ & 97 & $93(96.7 \pm 1.6)$ & $87(91.3 \pm 3.8)^{\mathrm{c}}$ & $84(89.3 \pm 4.3)^{\mathrm{c}}$ & $79(80.1 \pm 3.9)^{\mathrm{c}}$ \\
\hline
\end{tabular}

$n$ : Total number of presumptive zygotes placed in culture. K: Represents $1 \times 10^{3}$.

*Data are presented as $n\left(\% \pm\right.$ S.E.). ${ }^{a, b, c}$ Values in the same column with different superscripts differ significantly $(P<0.05)$.

The expression levels of three genes related with membrane trafficking (AQP3, AQP11 and ATP1A1), two genes related to metabolism (LDLR and $\angle D H A)$ and four genes involved in epigenetics (DNMT3A, IGF2R, GRB10 and SNRPN) were determined in blastocysts cultured in the presence $(\mathrm{C}+)$ or absence $(\mathrm{C}-)$ of FCS or supplemented with EV from OF from the isthmus enriched either at $10 \mathrm{~K}$ (Isthmus $10 \mathrm{~K}$ ) or $100 \mathrm{~K}$ (Isthmus $100 \mathrm{~K}$ ) (Figs 3 and 4). The addition of $100 \mathrm{~K}$ isthmus EV induced a significant upregulation of the water channel $A Q P 3, D N M T 3 A$ and SNRPN genes compared with the group supplemented with serum $(\mathrm{C}+)$, whereas blastocysts cultured with BSA $(\mathrm{C}-)$ showed intermediate but not significantly different levels. The lipid receptor $L D L R$ was significantly downregulated in $\mathrm{C}+$ compared with the rest of the groups. The remaining genes analyzed displayed no differences among groups.

\section{Discussion}

In this study, we report that the in vitro culture of bovine embryos with OF-EV from the isthmus, in the absence of serum improves the quality of the produced embryos. We found that embryo development was not affected by

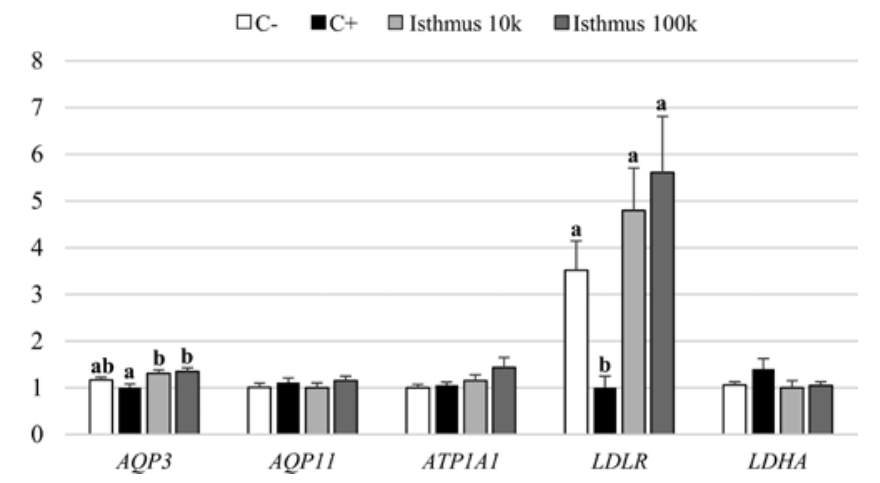

Figure 3 Relative mRNA transcription in bovine in vitro blastocysts (D7-8 p.i.) cultured with OF-EV (isthmus) isolated at different g-forces (10-100K) of genes related with membrane trafficking (AQP3, AQP11, ATP1A1) and metabolism (LDLR and LDHA). Data are relative to mean of internal gene H2AFZ. Data presented are mean \pm S.E. ${ }^{a}, b$ Different superscripts indicate significant differences for each gene $(P<0.05)$. the presence of OF-EV, but the quality of the produced embryos in terms of cryotolerance and the expression of genes related to metabolism and epigenetics were improved. To our knowledge, this is the first attempt at isolating and characterizing EV from the ampullary and isthmic OF and evaluating their effect during in vitro culture.

The first stages of early bovine embryo development occur in the oviduct, where the embryo spends around 4 days (Hackett et al. 1993). The OF comprises the secretions of BOEC and the transudation into the oviduct lumen of blood plasma (Ellington 1991). To date, the effect of bovine OF in vitro has been evidenced in porcine- and bovine-matured oocytes in terms of ZP modulation and embryo quality (Coy et al. 2008, Lloyd et al. 2009, Cebrian-Serrano et al. 2013); and during in vitro culture of bovine zygotes with a positive effect on embryo development and quality (LoperaVasquez et al. 2015).

The EVs are membrane vesicles secreted by most cell types that are nowadays considered mechanisms of intercellular communication (Yanez-Mo et al. 2015). Different EV populations associate different morphological characteristics and RNA profiles (Lötvall et al. 2014). The analyses by NTA of the size

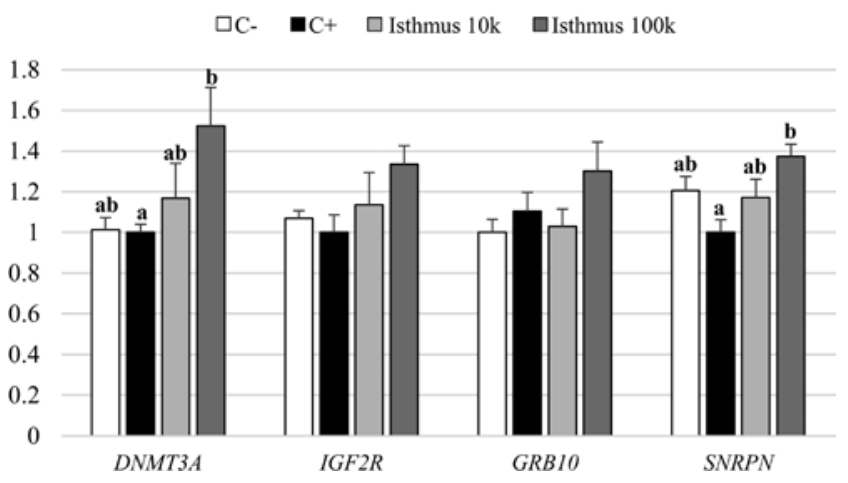

Figure 4 Relative mRNA transcription in bovine in vitro blastocysts (D7-8 p.i.) cultured with OF-EV (Isthmus) isolated at different g-forces (10-100K) of genes related with epigenetics (DNMT3A, $I G F 2 R, G R B 10$ and $S N R P N)$. Data are relative to mean of internal gene H2AFZ. Data presented are mean \pm S.E. ${ }^{a, b}$ Different superscripts indicate significant differences for each gene $(P<0.05)$. 
and concentration of EV from maternal reproductive tract show that they are heterogeneous. Human follicular fluid EV are polydisperse, including MV and exosome-sized $\mathrm{EV}$, with an average of $\approx 220 \mathrm{~nm}$ and a mean concentration of $\approx 2.7 \times 10^{6} \mathrm{EV} / \mathrm{mL}$ (Tannetta et al. 2014). In ovine uterine fluid, EVs showed a mean size of $\approx 148 \mathrm{~nm}$ in $\mathrm{a} \approx 200 \times 10^{9} \mathrm{EV} / \mathrm{mL}$ (Burns et al. 2014). Our samples also presented polydispersed populations. NTA analyses revealed a broadly distributed population in the $10 \mathrm{~K}$ pellet and a more narrow and smaller-sized distribution in the $100 \mathrm{~K}$ pellet, even though the mean size of both samples was not significantly different irrespective the $\boldsymbol{g}$ force used for isolation. Moreover, the concentration of small vesicles was greatly increased in the early phase of the cycle, and predominant at the isthmus, whereas in the ampulla, vesicles were more or less equally divided in the $10 \mathrm{~K}$ and the $100 \mathrm{~K}$ pellet. This may be explained by the fact that the isthmus is the part of the oviduct where the embryo develops in vivo, up to $\geq 16$ cell stage, before entering the uterus and that the vesicles are responsible for the interaction between the oviduct and the early embryo.

The role of EV present in the reproductive tract is a recent field of research. Silveira and coworkers (Silveira et al. 2012) isolated MV and exosomes of equine ovarian follicular fluid and evidenced the presence of proteins and miRNAs that were present in the follicular cells, suggesting EVs play an important role in cell-tocell communication within the mammalian ovarian follicle (Silveira et al. 2012). Sohel and coworkers (Sohel et al. 2013) demonstrated a miRNA transport mediated by exosome and non-exosome structures in bovine follicular microenvironment, associating the extracellular miRNA with the growth status of the oocyte (Sohel et al. 2013). Using an in vitro model, $\mathrm{Ng}$ and coworkers ( $\mathrm{Ng}$ et al. 2013) identified and examined the presence and role of EV of the uterine cavity. The miRNA present in the uterine EV allowed a bioinformatic identification of pathways possibly influenced after the EV uptake by trophectoderm or endometrial epithelium at the time of implantation or after sperm transfer during the transit across the uterus (Ng et al. 2013). Burns and coworkers (Burns et al. 2014) evidenced the presence of $E V$ in the uterine fluid of pregnant and cyclic ewes. The differences identified in the molecular contents determined by the pregnancy status suggested different EV sources (endometrium conceptus), supporting the idea that EV in the uterine fluid plays a relevant role in the establishment and maintenance of pregnancy (Burns et al. 2014). The same group clearly demonstrated the function of EVs from conceptus trophectoderm and uterine epithelia in conceptus elongation and conceptusendometrial interactions during early pregnancy in sheep (Burns et al. 2016). Al-Dossary and coworkers (Al-Dossary et al. 2013) revealed the expression and secretion via oviductal exosomes of plasma membrane
$\mathrm{Ca}^{2+}$-ATPase 4a (PMCA4a-Ca ${ }^{2+}$ homeostasis) in the female reproductive tissues and luminal fluids during estrous, and their uptake by sperm with a possible role in sperm viability during storage in the oviduct, capacitation and acrosome reaction (Al-Dossary et al. 2013).

In spite of the recent efforts made to elucidate the function of EVs during reproductive events, the role of bovine OF-EV in early embryo development is still unknown. Our results show for the first time that EV can be isolated from the isthmus of the bovine oviduct at the early luteal phase and can be used successfully during in vitro culture with developmental rates similar to serum-containing media. In a similar in vitro system, we recently demonstrated a positive effect of EV secreted by BOEC monolayer on the developmental capacity of bovine zygotes and the quality of the produced embryos in vitro (Lopera-Vásquez et al. 2016). Data from this study, in which we assessed different EV doses (as low as $7.5 \times 10^{4}$ ), showed no significant differences, indicating that we may be probably working at saturating conditions in this in vitro conditions. In addition, we could also demonstrate that some of the deleterious effects of serum were reduced by the presence of EVs extracted from BOEC cultures in vitro (Lopera-Vásquez et al. 2016). Here, the quality of the blastocysts cultured with isthmus-100 K OF-EV was higher than that of blastocysts produced in semi-defined media with serum or BSA in terms of cryotolerance. This effect may be possibly due to cell-cell communication mechanisms related to the dialog between the oviduct and the early embryo. Thus, it is not surprising that the positive effect is mostly observed with the small vesicle population recovered from the isthmus, the part of the oviduct where in vivo the early embryo develop up to $\geq 16$ cell stage. Interestingly, the number of small vesicles greatly increases in the early phase of the oestrous cycle, when most likely an oviduct-embryo interaction takes place. Thus, the OF complexity is associated with the dynamic nature of oviductal epithelial cell populations at different stages of estrous cycle (Yániz et al. 2000). This is in agreement with a recent study from our group (Maillo et al. 2016) that identified 2287 genes differentially expressed between ampulla and isthmus in pregnant animals after characterization of the bovine oviductal transcriptome on Day 3 between cyclic and pregnant heifers.

A plausible molecular explanation for the increased survival rates after vitrification in the isthmic OF-EV is the upregulation of the water channel $A Q P 3$. However, the difference with the $\mathrm{C}$ - group was not significant, suggesting an additional role of serum in the regulation of this gene. In a previous study, we also detected a significant upregulation of $A Q P 3$ in blastocysts cultured in the presence of oviductal fluid, which also exhibited higher cryotolerance than those cultured in the presence of serum (Lopera-Vasquez et al. 2015). Aquaporins selectively conduct water molecules allowing the 
rapid movement of water through the membrane and thereby facilitating survival after freezing and thawing. In particular, the artificial expression of AQP3 in mouse oocytes (Edashige et al. 2003) improved survival after cryopreservation and AQP3 has been proposed as a major water and cryoprotectant transporter in bovine morulae (Jin et al. 2011). In contrast, two other genes related with membrane trafficking, another aquaporin (AQP11) and the Na/k-ATPase $\alpha-1$-subunit (ATP1A1), essential for blastocyst expansion in mice (Barcroft et al. 2004), did not differ between groups. We also analyzed the expression of a lipid receptor $(L D L R)$ and a glycolytic enzyme (LDHA) that has been related with anaerobic glycolysis in bovine cumulus cells (BermejoAlvarez et al. 2010). LDHA did not display significant differences between groups, but $L D L R$ was significantly downregulated in the presence of serum compared with the other groups. This result is in agreement with our previous findings in bovine embryos (LoperaVasquez et al. 2015) and may be the consequence of higher amount of lipids in the serum supplemented media. In this perspective, $L D L R$ has been reported to be downregulated in embryos derived from obese mice, and it was proposed as a regulator of lipid uptake in blastocysts (Bermejo-Alvarez et al. 2012).

Finally, the de novo DNA methyltransferase DNMT3A and the imprinted gene SNRPN were downregulated in the group supplemented with serum compared with isthmic $100 \mathrm{~K}$ OF-EV. However, the imprinted gene $I G F 2 R$ and the putatively imprinted gene GRB10 did not reveal significant differences, although did show a similar trend. Altered expression patterns of imprinted genes may be indicative of imprinting disorders. Imprinting disorders caused by artificial reproductive techniques are known to cause phenotypic alterations in the offspring such as the large offspring syndrome (Young et al. 2001). In particular, abnormal SNRPN imprinting causes Prader-Willi syndrome in humans (Özçelik et al. 1992). Similar to humans, bovine SNRPN is a paternally expressed imprinted gene (Lucifero et al. 2006), and its expression is positively linked with methylation in bovine. Thus, a reduced expression of DNMT3A may have caused a reduction in methylation and expression of $S N R P N$, similar to the one observed in bovine placenta derived from IVF embryos compared with Al (Suzuki et al. 2009).

In conclusion, bovine OF-EV can be isolated from the isthmus by ultracentrifugation at $100 \mathrm{~K}$ and used in in vitro embryo culture with a positive effect on embryo quality, reflected in cryotolerance. Regarding gene expression patterns, significant differences of important genes related with metabolism, epigenetics and water channel traffic were observed compared with the group cultured in the presence of serum. The presence of isthmus-100 K OF-EV also slightly increased the abundance of some of these genes compared with the no-serum control. These results provide evidence of the essential association of the oviductal environment and developing embryo confirming an early embryo-maternal dialog. Further studies of OF-EV characterization will elucidate possible mechanisms of communication between the mother and the embryo mediated by the EV.

\section{Declaration of interest}

The authors declare that there is no conflict of interest that could be perceived as prejudicing the impartiality of the research reported.

\section{Funding}

This study was supported by the Spanish Ministry of Economy and Competitiveness (D R: AGL2012-37510 and AGL201570140-R; A G A: AGL2015-66145-R; P B A: AGL2014-58739-R and RYC-2012-10193); M Y-M: BFU2014-55478-R and RYC2012-11025; R L V: FPI scholarship BES-2010-031873.

\section{Acknowledgments}

The authors thank Valeriano Lloreda, Carolina Nunez and Paula Beltran for their constant laboratory assistant and the Spanish Association of breeders of selected cattle of the Asturian Valley breed (ASEAVA) for providing the semen used in this work. The authors thank Dr Pat Lonergan from University College Dublin for his critical reading of the manuscript.

\section{References}

Abe H \& Hoshi H 1997 Bovine oviductal epithelial cells: their cell culture and applications in studies for reproductive biology. Cytotechnology $\mathbf{2 3}$ 171-183. (doi:10.1023/A:1007929826186)

Al-Dossary AA, Strehler EE \& Martin-DeLeon PA 2013 Expression and secretion of plasma membrane Ca2+-ATPase 4a (PMCA4a) during murine estrus: association with oviductal exosomes and uptake in sperm. PLOS ONE 8 e80181. (doi:10.1371/journal.pone.0080181)

Barcroft LC, Moseley AE, Lingrel JB \& Watson AJ 2004 Deletion of the $\mathrm{Na} / \mathrm{K}$-ATPase $\alpha 1$-subunit gene (Atp1a1) does not prevent cavitation of the preimplantation mouse embryo. Mechanisms of Development 121 417-426. (doi:10.1016/j.mod.2004.04.005)

Bermejo-Álvarez P, Rizos D, Rath D, Lonergan P \& Gutierrez-Adan A 2008 Epigenetic differences between male and female bovine blastocysts produced in vitro. Physiological Genomics 32 264-272. (doi:10.1152/ physiolgenomics.00234.2007)

Bermejo-Alvarez P, Rizos D, Rath D, Lonergan P \& Gutierrez-Adan A 2010 Sex determines the expression level of one third of the actively expressed genes in bovine blastocysts. PNAS 107 3394-3399. (doi:10.1073/ pnas.0913843107)

Bermejo-Alvarez P, Rosenfeld CS \& Roberts RM 2012 Effect of maternal obesity on estrous cyclicity, embryo development and blastocyst gene expression in a mouse model. Human Reproduction 27 3513-3522. (doi:10.1093/humrep/des327)

Burns G, Brooks K, Wildung M, Navakanitworakul R, Christenson LK \& Spencer TE 2014 Extracellular vesicles in luminal fluid of the ovine uterus. PLoS ONE 9 e90913. (doi:10.1371/journal.pone.0090913)

Burns GW, Brooks KE \& Spencer TE 2016 Extracellular vesicles originate from the conceptus and uterus during early pregnancy in sheep. Biology of Reproduction 94 56. (doi:10.1095/biolreprod.115.134973)

Cebrian-Serrano A, Salvador I, García-Roselló E, Pericuesta E, Pérez-Cerezales S, Gutierrez-Adán A, Coy P \& Silvestre M 2013 Effect of the bovine oviductal fluid on in vitro fertilization, development 
and gene expression of in vitro-produced bovine blastocysts. Reproduction in Domestic Animals 48 331-338. (doi:10.1111/j.14390531.2012.02157.x)

Cordova A, Perreau C, Uzbekova S, Ponsart C, Locatelli Y \& Mermillod P 2014 Development rate and gene expression of IVP bovine embryos cocultured with bovine oviduct epithelial cells at early or late stage of preimplantation development. Theriogenology $\mathbf{8 1} 1163-1173$. (doi:10.1016/j.theriogenology.2014.01.012)

Coy P, Cánovas S, Mondéjar I, Saavedra MD, Romar R, Grullón L, Matás C \& Avilés M 2008 Oviduct-specific glycoprotein and heparin modulate sperm-zona pellucida interaction during fertilization and contribute to the control of polyspermy. PNAS 105 15809-15814. (doi:10.1073/ pnas.0804422105)

Coy P, García-Vázquez FA, Visconti PE \& Avilés M 2012 Roles of the oviduct in mammalian fertilization. Reproduction 144 649-660. (doi:10.1530/REP-12-0279)

Edashige K, Yamaji Y, Kleinhans FW \& Kasai M 2003 Artificial expression of aquaporin-3 improves the survival of mouse oocytes after cryopreservation. Biology of Reproduction 68 87-94. (doi:10.1095/ biolreprod.101.002394)

Ellington JE 1991 The bovine oviduct and its role in reproduction: a review of the literature. Cornell Veterinarian 81 313-328.

Ghersevich S, Massa E \& Zumoffen C 2015 Oviductal secretion and gamete interaction. Reproduction 149 R1-R14. (doi:10.1530/REP-14-0145)

Hackett AJ, Durnford R, Mapletoft RJ \& Marcus GJ 1993 Location and status of embryos in the genital tract of superovulated cows 4 to 6 days after insemination. Theriogenology 40 1147-1153. (doi:10.1016/0093691X(93)90285-D)

Holm P, Booth PJ, Schmidt MH, Greve T \& Callesen H 1999 High bovine blastocyst development in a static in vitro production system using SOFaa medium supplemented with sodium citrate and myo-inositol with or without serum-proteins. Theriogenology 52 683-700. (doi:10.1016/ S0093-691X(99)00162-4)

Jin B, Kawai Y, Hara T, Takeda S, Seki S, Nakata Y-I, Matsukawa K, Koshimoto C, Kasai M \& Edashige K 2011 Pathway for the movement of water and cryoprotectants in bovine oocytes and embryos. Biology of Reproduction 85 834-847. (doi:10.1095/biolreprod.110.088641)

Killian G 2011 Physiology and endocrinology symposium: evidence that oviduct secretions influence sperm function: a retrospective view for livestock. Journal of Animal Science 89 1315-1322. (doi:10.2527/ jas.2010-3349)

Lazzari G, Wrenzycki C, Herrmann D, Duchi R, Kruip T, Niemann H \& Galli C 2002 Cellular and molecular deviations in bovine in vitroproduced embryos are related to the large offspring syndrome. Biology of Reproduction 67 767-775. (doi:10.1095/biolreprod.102.004481)

Leese HJ, Hugentobler SA, Gray SM, Morris DG, Sturmey RG, Whitear S \& Sreenan JM 2007 Female reproductive tract fluids: composition, mechanism of formation and potential role in the developmental origins of health and disease. Reproduction, Fertility and Development 20 1-8. (doi:10.1071/RD07153)

Lonergan P 2007 State-of-the-art embryo technologies in cattle. Society of Reproduction and Fertility Supplement 64 315-325. (doi:10.5661/rdrvi-315)

Lonergan P \& Fair T 2008 In vitro-produced bovine embryosdealing with the warts. Theriogenology 69 17-22. (doi:10.1016/j. theriogenology.2007.09.007)

Lopera-Vasquez R, Hamdi M, Maillo V, Lloreda V, Coy P, Gutierrez-Adan A, Bermejo-Alvarez P \& Rizos D 2015 Effect of bovine oviductal fluid on development and quality of bovine embryos produced in vitro. Reproduction, Fertility and Development In Press. (doi:10.1071/rd15238)

Lopera-Vásquez R, Hamdi $M$, Fernandez-Fuertes B, Maillo V, Beltrán-Breña $P$, Calle $A$, Redruello A, López-Martín S, Gutierrez-Adán A, Yañez-Mó M et al. 2016 Extracellular vesicles from BOEC in in vitro embryo development and quality. PLOS ONE 11 e0148083. (doi:10.1371/journal.pone.0148083)

Lötvall J, Hill AF, Hochberg F, Buzás EI, Di Vizio D, Gardiner C, Gho YS, Kurochkin IV, Mathivanan S, Quesenberry P et al. 2014 Minimal experimental requirements for definition of extracellular vesicles and their functions: a position statement from the International Society for Extracellular Vesicles. Journal of Extracellular Vesicles 3 26913. (doi:10.3402/jev.v3.26913)
Lucifero D, Suzuki J, Bordignon V, Martel J, Vigneault C, Therrien J, Filion F, Smith LC \& Trasler JM 2006 Bovine SNRPN methylation imprint in oocytes and day 17 in vitro-produced and somatic cell nuclear transfer embryos. Biology of Reproduction 75 531-538. (doi:10.1095/ biolreprod.106.051722)

Lloyd RE, Romar R, Matás C, Gutiérrez-Adán A, Holt WV \& Coy P 2009 Effects of oviductal fluid on the development, quality, and gene expression of porcine blastocysts produced in vitro. Reproduction 137 679-687. (doi:10.1530/REP-08-0405)

Maillo V, de Frutos C, O'Gaora P, Forde N, Burns GW, Spencer TE, Gutierrez-Adan A, Lonergan P \& Rizos D 2016 Spatial differences in gene expression in the bovine oviduct. Reproduction 152 37-46. (doi:10.1530/rep-16-0074)

Menezo Y \& Guerin P 1997 The mammalian oviduct: biochemistry and physiology. European Journal of Obstetrics and Gynecology and Reproductive Biology 73 99-104. (doi:10.1016/S03012115(97)02729-2)

Mondéjar I, Martínez-Martínez I, Avilés M \& Coy P 2013 Identification of potential oviductal factors responsible for zona pellucida hardening and monospermy during fertilization in mammals. Biology of Reproduction 89 67. (doi:10.1095/biolreprod.113.111385)

Ng YH, Rome S, Jalabert A, Forterre A, Singh $\mathrm{H}$, Hincks CL \& Salamonsen LA 2013 Endometrial exosomes/microvesicles in the uterine microenvironment: a new paradigm for embryo-endometrial cross talk at implantation. PLOS ONE 8 e58502. (doi:10.1371/journal. pone.0058502)

Niemann H \& Wrenzycki C 2000 Alterations of expression of developmentally important genes in preimplantation bovine embryos by in vitro culture conditions: implications for subsequent development. Theriogenology 53 21-34. (doi:10.1016/S0093-691X(99)00237-X)

Özçelik T, Leff S, Robinson W, Donlon T, Lalande M, Sanjines E, Schinzel A \& Francke U 1992 Small nuclear ribonucleoprotein polypeptide $N$ (SNRPN), an expressed gene in the Prader-Willi syndrome critical region. Nature Genetics 2 265-269. (doi:10.1038/ ng1292-265)

Piehl LL, Fischman ML, Hellman U, Cisale H \& Miranda PV 2013 Boar seminal plasma exosomes: Effect on sperm function and protein identification by sequencing. Theriogenology $\mathbf{7 9}$ 1071-1082. (doi:10.1016/j.theriogenology.2013.01.028)

Plourde D, Vigneault C, Laflamme I, Blondin P \& Robert C 2012 Cellular and molecular characterization of the impact of laboratory setup on bovine in vitro embryo production. Theriogenology 77 1767-1778. e1761. (doi:10.1016/j.theriogenology.2011.12.021)

Pontes JHF, Nonato-Junior I, Sanches BV, Ereno-Junior JC, Uvo S, Barreiros TRR, Oliveira JA, Hasler JF \& Seneda MM 2009 Comparison of embryo yield and pregnancy rate between in vivo and in vitro methods in the same Nelore (Bos indicus) donor cows. Theriogenology 71 690-697. (doi:10.1016/j.theriogenology.2008.09.031)

Raposo G \& Stoorvogel W 2013 Extracellular vesicles: exosomes, microvesicles, and friends. Journal of Cell Biology 200 373-383. (doi:10.1083/jcb.201211138)

Rizos D, Ward F, Duffy P, Boland MP \& Lonergan P 2002 Consequences of bovine oocyte maturation, fertilization or early embryo development in vitro versus in vivo: Implications for blastocyst yield and blastocyst quality. Molecular Reproduction and Development 61 234-248. (doi:10.1002/mrd.1153)

Rizos D, Gutiérrez-Adán A, Pérez-Garnelo S, Fuente Jdl, Boland MP \& Lonergan P 2003 Bovine embryo culture in the presence or absence of serum: implications for blastocyst development, cryotolerance, and messenger RNA expression. Biology of Reproduction 68 236-243. (doi:10.1095/biolreprod.102.007799)

Rizos D, Clemente M, Bermejo-Alvarez P, De La Fuente J, Lonergan P \& Gutiérrez-Adán A 2008 Consequences of in vitro culture conditions on embryo development and quality. Reproduction in Domestic Animals 43 44-50. (doi:10.1111/j.1439-0531.2008.01230.x)

Rizos D, Ramirez MA, Pintado B, Lonergan P \& Gutierrez-Adan A 2010 Culture of bovine embryos in intermediate host oviducts with emphasis on the isolated mouse oviduct. Theriogenology 73 777-785. (doi:10.1016/j.theriogenology.2009.10.001)

Rodriguez-Martinez H 2007 Role of the oviduct in sperm capacitation. Theriogenology $\mathbf{6 8}$ (Supplement 1) S138-S146. (doi:10.1016/j. theriogenology.2007.03.018) 
Saadeldin IM, Kim SJ, Choi YB \& Lee BC 2014 Improvement of cloned embryos development by co-culturing with parthenotes: a possible role of exosomes/microvesicles for embryos paracrine communication. Cellular Reprogramming 16 223-234. (doi:10.1089/cell.2014.0003)

da Silveira JC, Veeramachaneni DNR, Winger QA, Carnevale EM \& Bouma GJ 2012 Cell-secreted vesicles in equine ovarian follicular fluid contain miRNAs and proteins: a possible new form of cell communication within the ovarian follicle. Biology of Reproduction $\mathbf{8 6}$ 71. (doi:10.1095/biolreprod.111.093252)

Simons M \& Raposo G 2009 Exosomes - vesicular carriers for intercellular communication. Current Opinion in Cell Biology 21 575-581. (doi:10.1016/j.ceb.2009.03.007)

Simpson RJ, Jensen SS \& Lim JWE 2008 Proteomic profiling of exosomes: current perspectives. Proteomics 8 4083-4099. (doi:10.1002/ pmic.200800109)

Sohel MMH, Hoelker M, Noferesti SS, Salilew-Wondim D, Tholen E, Looft C, Rings F, Uddin MJ, Spencer TE, Schellander K et al. 2013 Exosomal and non-exosomal transport of extra-cellular microRNAs in follicular fluid: implications for bovine oocyte developmental competence. PLOS ONE 8 e78505. (doi:10.1371/journal. pone.0078505)

Suzuki J, Therrien J, Filion F, Lefebvre R, Goff AK \& Smith LC 2009 In vitro culture and somatic cell nuclear transfer affect imprinting of SNRPN gene in pre- and post-implantation stages of development in cattle. BMC Developmental Biology 9 9. (doi:10.1186/1471-213X-9-9)

Tannetta D, Dragovic R, Alyahyaei Z \& Southcombe J 2014 Extracellular vesicles and reproduction-promotion of successful pregnancy. Cellular and Molecular Immunology 11 548-563. (doi:10.1038/ cmi.2014.42)

Théry C, Amigorena S, Raposo G \& Clayton A 2006. Isolation and characterization of exosomes from cell culture supernatants and biological fluids. Current Protocols in Cell Biology 30:3.22:3.22.13.22.29. (doi:10.1002/0471143030.cb0322s30)
Théry C, Ostrowski M \& Segura E 2009 Membrane vesicles as conveyors of immune responses. Nature Reviews Immunology 9 581-593. (doi:10.1038/nri2567)

Tse P-K, Lee Y-L, Chow W-N, Luk JMC, Lee K-F \& Yeung WSB 2008 Preimplantation embryos cooperate with oviductal cells to produce embryotrophic inactivated complement-3b. Endocrinology 149 1268-1276. (doi:10.1210/en.2007-1277)

Witwer KW, Buzás EI, Bemis LT, Bora A, Lässer C, Lötvall J, Hoen ENN-t, Piper MG, Sivaraman S, Skog J et al. 2013 Standardization of sample collection, isolation and analysis methods in extracellular vesicle research. Journal of Extracellular Vesicles 2. PubMed: 20630 (doi:10.3402/jev.v2i0.20360)

Yañez-Mó M, Siljander PR, Andreu Z, Zavec AB, Borras FE, Buzas EI, Buzas K, Casal E, Cappello F, Carvalho J et al. 2015 Biological properties of extracellular vesicles and their physiological functions. Journal of Extracellular Vesicles 4 27066. (doi:10.3402/jev. v4.27066)

Yániz JL, Lopez-Gatius F, Santolaria P \& Mullins KJ 2000 Study of the functional anatomy of bovine oviductal mucosa. Anatomical Record 260 268-278. (doi:10.1002/1097-0185(20001101)260:3<268::aid$\operatorname{ar60}>3.0 .(0 ; 2-I)$

Young LE, Fernandes K, McEvoy TG, Butterwith SC, Gutierrez CG, Carolan C, Broadbent PJ, Robinson JJ, Wilmut I \& Sinclair KD 2001 Epigenetic change in IGF2R is associated with fetal overgrowth after sheep embryo culture. Nature Genetics 27 153-154. (doi:10.1038/84769)

Received 15 July 2016

First decision 8 August 2016

Revised manuscript received 4 January 2017

Accepted 19 January 2017 